\title{
ESTUDO DE UMA CEPA HUMANA DE SCHISTOSOMA MANSONI RESISTENTE A AGENTES ESQUISTOSSOMICIDAS *
}

\author{
Naftale Katz, E. P. Dias, Neusa Araujo e C. P. Souza
}

\begin{abstract}
Foi isolada uma cepa de Schistosoma mansoni proveniente de dois pacientes tratados com hycanthone, por duas vezes, na dose de $2,5 \mathrm{mg} / \mathrm{kg}, i . \mathrm{m}$., em janeiro e em abril de 1970, e com niridazole $(25 \mathrm{mg} / \mathrm{kg}$ dia $x 5$ oral), em abril de 1971. o numero de ovos por grama de fezes nestes pacientes antes do tratamento era de 2675 e 1025, respectivamente e, após o terceiro tratamento, em torno de 100 ovos/g.

Miracídios obtidos das fezes destes pacientes, infectaram caramujos (Biomphalaria glabrata), que passaram a eliminar cercárias (cepa WW). Estas foram utilizadas para infeç̧āo experimental de camundongos albinos. Os animais infectados foram tratados com esquemas múltiplos de hycanthone, niridazole $e$ oxamniquine.

Estudos comparativos das cepas WW e LE (esta última mantida rotineiramente em nossos laboratórios) mostraram diferenças acentuadas quando à sensibilidade aos esquistossomicidas usados. De fato, com hycanthone, na dose de $80 \mathrm{mg} / \mathrm{kg}, \mathrm{i} . \mathrm{m}$. houve $100 \%$ de alteração do oograma nos camundongos infectados com a cepa L.E. e de 0,0\% nos infectados com a cepa WW. Com a oxamniquine e niridazole as diferenças foram menores, mas, ainda assim, suficientes para indicar maior resistência da cepa WW a estes esquistossomicidas.

Esta é a primeira vez na literatura, que se demonstra resistência em cepas de $\mathrm{S}$. mansoni provenientes de pacientes tratados.
\end{abstract}

\section{INTRODUÇÃO}

Em trabalho anterior estudamos $28 \mathrm{pa}-$ cientes com período de infeç̧ão esquistossomótica conhecido e que foram tratados com hycanthone, $\epsilon \mathrm{m}$ diferentes épocas após o contágio. De 15 pacientes tratados, 2 a 8 meses após o contágio, apenas 6 $(40 \%)$ se curaram [Katz (4)]. Os 9 pacientes não curados foram novamente tratados com hycanthone, na mesma dose, isto é, $2,5 \mathrm{mg} / \mathrm{kg}$, i.m., 4 a 9 meses após o primeiro tratamento. Destes, 7 ficaram curados e 2 continuaram eliminando ovos viáveis de $S$. mansoni nas fezes. Estes 2 pa- cientes foram tratados pela terceira vez com niridazole (Ambilhar) e o controle parasitológico posterior mostrou que, ainda desta vez, não haviam sido curados.

No presente trabalho são discutidos os resultados obtidos em camundongos experimentalmente infectados com a cepa obtida destes pacientes, e tratados com três drcgas sabidamente esquistossomicidas.

\section{MATERIAL E MÉTODOS}

Dois pacientes (14 e 13 anos de idade) foram tratados pela primeira vez em janeiro de 1970, 7 meses após o contágio, com

\footnotetext{
* Trabalho do Centro de Pesquisas "René Rachou", INERu - FToCRUz e Seçáo de Parasitoses da Prefettura de Belo Hortzonte, realizado com auxillo do Conselho Nacional de Pesquisas.

Enderêço: INERu - Calxa Postal, 1743 - 30000 B. Hte. - Brasil

Recebido para publicação em 20-7-1973.
} 
hycanthone na dose de $2,5 \mathrm{mg} / \mathrm{kg}, 1 . \mathrm{m}$.. Pela segunda vez, em abril de 1970, com a mesma dose de hycanthone e, finalmente, pela terceira vez, em abril de 1971, com niridazole $(25 \mathrm{mg} / \mathrm{kg} /$ dia $\times 5)$, o último tratamento teve que ser interrompido no quinto dia, uma vez que os pacientes apresentaram quadro de alucinação e/ou convulsão. Para o controle parasitológico foi utilizado o método de Ka to quantitativo (5).

Miracídios obtidos das fezes destes pacientes, no principio de 1973 , infectaram Biomphalaria glabrata no laboratório, que passaram a eliminar cercárias (cepa WW), utilizadas para infecção experimental de camundongos albinos. As técnicas utilizadas foram aquelas já anteriormente descritas [Pellegrino \& Katz (7)].

Quarenta e cinco dias após a infecção, grupos de 10 camundongos foram tratados com hycanthone $(80$ e $20 \mathrm{mg} / \mathrm{kg}$, i.m.), niridazole $(100$ e $50 \mathrm{mg} / \mathrm{kg} /$ dia $\times 5$, oral) e oxamniquine $(100$ e $50 \mathrm{mg} / \mathrm{kg}$ dose única, i.m.).

O grupo controle foi constituído por camundongos albinos experimentalmente infectados com o mesmo número de cercárias, isto é, $100 \pm 20$ porém da cepa $L E$. Esta cepa, mantida há vários anos em nossos laboratórios, provém de um paciente esquistossomótico de Belo Horizonte, não tratado.

Sete dias após o tratamento os animais foram sacrificados e os esquistossomos localizados nas veias mesentéricas e fígado, recuperados por perfusão. O estudo do oograma foi feito em fragmentos retirados do intestino delgado. Alterações do oograma foram consideradas significativas quando um ou mais estáglos correspondentes a ovos imaturos estavam ausentes. $O$ número de vermes mortos no fígado foi determinado após o esmagamento deste órgão entre duas placas de vidro e examinados ao microscópio de dissecção [Pellegrino \& Katz (7) ].

\section{RESULTADOS}

No gráfico I podem ser vistos os resultados obtidos nos dois pacientes tratados. O número de ovos por grama de fezes, antes do tratamento, era de 2675 e 1025 , respectivamente. Após o primeiro tratamento, passou a 915 e 167; após o segundo tratamento a 70 e 271 e após o terceiro trata- mento, conservou-se sempre em torno de 100 ovos/grama em ambos pacientes.

Os resultados obtidos após a administração do hycanthone, niridazole e oxamniquine em camundongos infectados experimentalmente com as cepas LE e WW podem ser vistos na Tabela I e II, respectivamente.

Quando foi administrado hycanthone na dose de $80 \mathrm{mg} / \mathrm{kg}$, i.m. nos camundongos infectados com a cepa LE foi observado que $100 \%$ dos animais apresentaram alterações do oograma (Tabela $I$ ). Dos animais infectados com a cepa wW nenhum apresentou parada da postura, em que pese o número de vermes deslocados para o fígado ter sido aproximadamente o mesmo com as duas cepas (em torno de $57 \%$ ) ( $\mathrm{Ta}$ belas I e II).

$\mathrm{Ccm}$ o niridazcle $(100 \mathrm{mg} / \mathrm{kg} /$ dia $\times 5$, oral), em $100 \%$ dos animais infectados com a cepa LE houve parada da postura e em $40 \%$ dos infectados com a cepa WW, e com a dose de $50 \mathrm{mg} / \mathrm{kg} /$ dia $\times 5$ oral foi de $40 \%$ e $11 \%$ respectivamente, com as cepas LE e WW. Considerando-se o número de vermes mortos encontrados no fígado, fol de $25 \%$ com a maior dose nos camundongos infectados com cepa LE e de apenas $2,6 \%$ nos infectados com a cepa WW. No de:locamento dos vermes para o fígado nāo foram observadas diferenças significativas com as duas cepas.

Após a administração de oxamniquine $(100 \mathrm{mg} / \mathrm{kg}$, dose única, i.m.) em $90 \%$ dos camundongos infectados com a cepa LEE houve parada da postura, enquanto que foi de $37 \%$ nos infectados com a cepa WW. Com a do:e de $50 \mathrm{mg} / \mathrm{kg}$, i.m. de oxaminiquine houve em $57 \%$ e $20 \%$ dos animais infectados com a cepa LE e WW, respectivamente, a parada da postura.

Em relação ao número de vermes mortos no figado foi de 31,1 e $3,9 \%$ respectivamente com as cepas LE e WW, quando se utilizou a maior dose de oxamniquine. Com a menor dose foi de 10,6 e $1,5 \%$, respectivamente. Com esta droga o deslocamento para o fígado foi também maior nos animais inoculados com a cepa LE.

\section{DISCUSSÃO}

Diferentes respostas terapêuticas de várias cepas a drogas esquistossomicidas tem sido relatada várias vezes. De fato, 
GRÁFICO - I

Números de ovos de S.monsoni por groma de fezes nos dois pacientes trotados com hyconthone e niridazole.

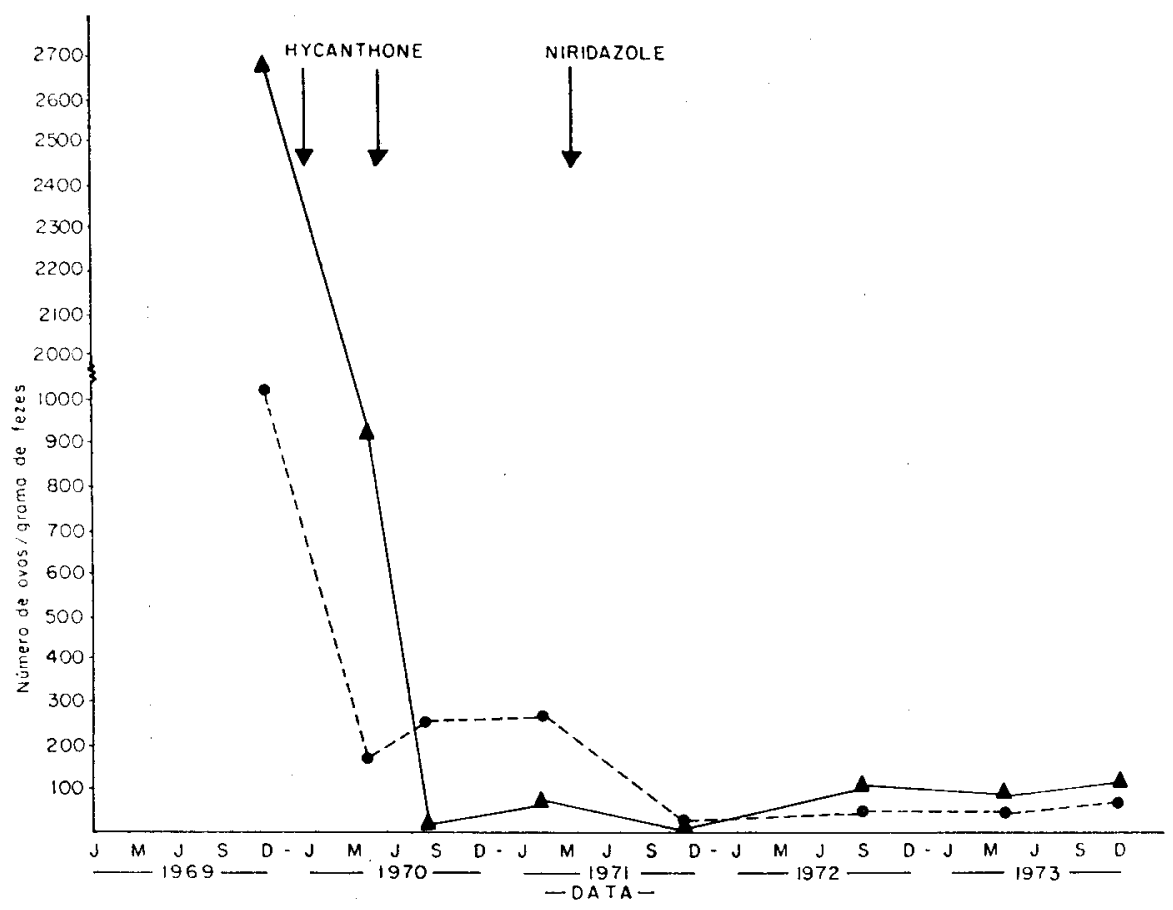

Gonnert \& Vogel (3) demonstraram que uma cepa de $S$. mansoni oriunda da Liberia era mais suscetivel que uma do Egito à ação parasiticida do lucanthone. Thompson et al. (9) também demonstraram diferença de atividade do pamoato de tris (P-aminofenil) carbonium em duas cepas diferentes. Mais recentemente, Lee et al (6) estudando cepas de S. mansoni de Porto Rico, Liberia, Belo Horizonte e Santa Lúcia, em camundongos experimentalmente infectados, puderam concluir que a cepa de Porto Rico era muito sensivel ao hycanthone e relativamente resistente ao stibofen. Bueding et al (2) estudando o comportamento de seis diferentes cepas de $S$. mansoni, sendo 3 de Porto Rico, e as outras, da Libéria, Tanzania e Santa Lúcia, em camundongos tratados com hycanthone $\mathbf{e}$ com um seu análogo (cloroindazol), observaram consideráveis diferenças na susceptibilidade das diferentes cepas às drogas utilizadas.

Em trabalho anterior, Rogers \& Bueding (8) tratando camundongos e hamsters infectados com uma cepa de Porto Rico com hycanthone $(60 \mathrm{mg} / \mathrm{kg})$ constataram que após 9 a 10 dias os vermes tinham migrado das veias mesentéricas para o figado. Qua- tro a 12 meses após o tratamento vermes vivos foram encontrados em mais de $90 \%$ dos animais tratados. Os esquistossomas recuperaram-se completamente e iniciaram novamente a postura de ovos, que infectaram caramujos. As gerações de vermes oriundos destes $\left(F_{1}\right.$ até $\left.F_{4}\right)$ mostraram estar resistentes a doses bem maiores de hycanthone pois não foram observados deslocamento para o fígado, lesão do sistema genital da fêmea, perda de pêso e/ou depleção do glicogênio nos vermes submetidos ao tratamento. $\mathbf{E}$ interessante observar que os esquistossomas hycanthone-resistentes apresentaram resistência cruzada a outras duas drogas relacionadas quimicamente, lucanthone e uma aminoalquiltetrahidroquinalina (oxamniquine), mas eram suscetíveis a um derivado nitrovinilfurânico (8). Yarinsky (1), repetindo estas experiências, com uma cepa diferente da usada por Rogers \& Bueding (8) e com doses menores da droga, obteve nas gerações descendentes, a mesma susceptibilidade ao hycanthone encontrada ao primeiro tratamento.

A cepa WW, que foi isolada de dois pacientes tratados por 3 vezes sem que fosse obtida a cura parasitológica, mostrou ser 
TABELA I: ATIVIDADE DE DROGAS ESQUISTOSSOMICIDAS EM CAMUNDONGOS EXPERIMENTALMENTE INFECTADOS PELA CEPA LE DE $S \cdot M A^{N} S O N I$

\begin{tabular}{|c|c|c|c|c|c|c|c|c|}
\hline \multirow{2}{*}{ Droga } & \multirow{2}{*}{$\begin{array}{l}\text { Equema de } \\
\text { tratamento } \\
\mathrm{mg} / \mathrm{kg} / \text { dia-via }\end{array}$} & \multicolumn{2}{|c|}{ Número de animais } & \multirow{2}{*}{$\begin{array}{l}\text { Média de } \\
\text { vermes }\end{array}$} & \multicolumn{3}{|c|}{ Distribuição de vermes - \% } & \multirow{2}{*}{$\begin{array}{c}\text { Alteração } \\
\text { do oograma } \\
\%\end{array}$} \\
\hline & & Tratados & Examinados & & Mesentério & Figado & $\begin{array}{c}\text { Mortos } \\
\text { no fígado }\end{array}$ & \\
\hline Hycantone & $\begin{array}{l}80 \times 1 \\
\text { i.m. }\end{array}$ & 10 & 6 & 16,1 & 42,4 & 57,6 & 1,3 & 100,0 \\
\hline Hycantone & $\begin{array}{l}20 \times 1 \\
\text { i.m. }\end{array}$ & 10 & 10 & 22,3 & 49,7 & 50,3 & 0,0 & 0,0 \\
\hline Niridazole & $\begin{array}{c}100 \times 5 \\
\text { oral }\end{array}$ & 10 & 10 & 6,8 & 61,7 & 38,3 & 25,0 & 100,0 \\
\hline Niridazole & $\begin{array}{c}50 \times 5 \\
\text { oral }\end{array}$ & 10 & 8 & 19,1 & 86,3 & 13,7 & 0,0 & 40,0 \\
\hline Oxamniquine & $\begin{array}{c}100 \times 1 \\
\text { i.m. }\end{array}$ & 10 & 9 & 24,0 & 18.1 & 81,9 & 31,1 & 90,0 \\
\hline Oxamniquine & $\begin{array}{c}50 \times 1 \\
\text { i.m. }\end{array}$ & 10 & 7 & 16,1 & 40,8 & 59,2 & 10,6 & 57,0 \\
\hline Controle & - & - & 10 & 34,2 & 83,2 & 16,8 & 0,0 & 0,0 \\
\hline
\end{tabular}


mais resistente ao hycanthone, niridazole e oxamniquine em camundongos experimentalmente infectados. De fato, com hycanthone, na dose de $80 \mathrm{mg} / \mathrm{kg}$, não foi observada alteração do cograma em nenhum dos animais infectados com a cepa WW, em contraste com a cepa LE, rotineiramente utilizada em nossos laboratórios onde houve parada da oviposição em $100 \%$ dos animais tratados. Maior resistência da cepa WW também foi demonstrada ao niridazole e oxamniquine.

Os dados até agora obtidos não permitem concluir se foi através de seleção ou de induçăo que foi obtida esta cepa mais resistente. De toda maneira, foi pela primeira vez na literatura que se demonstrou a possibilidade de existir uma cepa resistente a drogas comprovadamente esquistossomicidas oriundas de pacientes tratados com doses curativas. As implicações do aparecimento ou seleçăo de cepas resistentes, quando se considera o tratamento com esqu'stossomicida, em áreas endêmicas, são bastante óbvias e mostram a necessidađe de se prosseguirem estudos vizando o melhor conhecimento da resistência e suscetibilidade de cepas de $S$. mansoni oriundas de casos humanos.

\section{SUMMARY}

There has been isolated a Schistosoma mansoni strain from two patients submitted to two courses of treatment with hycanthone $(2.5 \mathrm{mg} / \mathrm{kg}, \mathrm{i.m}$.$) , in$ January and April, 1970, and to one course with niridazole $(25 \mathrm{mg} / \mathrm{kg} / \mathrm{day} x \mathrm{5}$, per os), in April, 1971. Before treatment, the number of eggs in the faeces of those patients was, per gram, 2,675 and 1,025, respectively; after completion of treatment, such number had come down to around 100 eggs/gram.

Miracidia hatched from the pationts faeces could infect Biomphalaria glabrata snails, which eliminated cercariae (WW strain) that were used for experimental infection of albino mice. The infected animals were, afterwards, treated with hycanthone, niridazole and oxamniquine under various schedules.

Comparative studies of $W W$ and $L E$ strains (the latter being routinoly kept in our laboratories) revealed marked differences in their sensitivity to the schistosomicides employed. Actually, after treatment with hysanthone, at the dosage of $80 \mathrm{mg} / \mathrm{kg}$, i.m., a $100 \%$ oogram changes were observed in the intestinal wall of mice inoculated with LE strain, whereas no alterations could be detected in the mice infected with $W W$ strain. As regards oxamniquine and niridazole the changes were smaller although still quite sufficient to indicate greater resistance of WW strain to these schistosomicides.

It is worth while remembering that, in the pertaining literature, it is the first time that resistance in $\mathbf{S}$. mansoni strains from treated patients has been demonstrated.

\section{REFERENCIAS BIBLIOGRÁFICAS}

1. ARCHER. S. \& YARINSKY, A. - Recent developments in the chemotherapy of schistosomiasis. Em "Prcgress in Drug Research", vol. 16 (Jucker. E. - ed.) pp. 12-16 Birkhäuser Verlag, Bassel and Stuttgart, 1972.

2. BUEDING, E., FISHER, J. \& BRUCE, J. - The antischistosomal activity of a chloroindazole analog of hycanthone in mice infected with Schistosoma man'oni. Pharmacol. Exp. Ther., 186: 402-407, 1973.

3. GONNERT, R. \& VOGEL, H. - Uber die Abhangigkeit des Therapieerfolges von Wirtsund Parasitrnstamm bei der experimentellen Schistosomiasis. $Z$. Tropenmed. Parasit., 6: 193-198, 1955.

4. KATZ, N. - Avaliação terapêutica do hvcanthone em pacientes com periodo 
TABELA II: ATIVIDADE DE DROGAS ESQUITOSSOMICIDAS EM CAMUNDONGOS EXPERIMENTALMENTE INFECTADOS PELA CEPA WW DE S. MANSONI

\begin{tabular}{|c|c|c|c|c|c|c|c|c|}
\hline \multirow{2}{*}{ Droga } & \multirow{2}{*}{$\begin{array}{c}\text { E quema de } \\
\text { tratamento } \\
\mathrm{mg} / \mathrm{kg} / \text { dia-via }\end{array}$} & \multicolumn{2}{|c|}{ Número de animais } & \multirow{2}{*}{$\begin{array}{l}\text { Média de } \\
\text { vermes }\end{array}$} & \multicolumn{3}{|c|}{ Distribuição de vermes - \% } & \multirow{2}{*}{$\begin{array}{c}\text { Alteração } \\
\text { do oograma } \\
\%\end{array}$} \\
\hline & & Tratados & Examinados & & Mesentério & Fígado & $\begin{array}{l}\text { Mortos } \\
\text { no fígado }\end{array}$ & \\
\hline Hycantone & $\begin{array}{c}80 \times 1 \\
1 . \mathrm{m} .\end{array}$ & 10 & 8 & 25,8 & 42,6 & 57,4 & 0,0 & 0,0 \\
\hline Hycantone & $\begin{array}{c}20 \times 1 \\
\text { i. } \mathrm{m} .\end{array}$ & 10 & 10 & 37,6 & 61,7 & 38,3 & 0,0 & 0,0 \\
\hline Niridazole & $\begin{array}{c}100 \times 5 \\
\text { oral }\end{array}$ & 10 & 10 & 15,3 & 63.3 & 36,7 & 2,6 & 40,0 \\
\hline Niridazole & $\begin{array}{c}50 \times 5 \\
\text { oral }\end{array}$ & 10 & 9 & 17,4 & 88,5 & 11,5 & 0,0 & 11,0 \\
\hline Oxamniquine & $\begin{array}{c}100 \times 1 \\
\text { i.m. }\end{array}$ & 10 & 8 & 15,8 & 44,9 & 55,1 & 3,9 & 37,0 \\
\hline Oxamniquine & $\begin{array}{c}50 \times 1 \\
\text { 1.m. }\end{array}$ & io & 10 & 19,3 & 65,8 & 34,2 & 1,5 & 20,0 \\
\hline Controle & - & - & 10 & 30,4 & 92,1 & 7,9 & 0,0 & 0,0 \\
\hline
\end{tabular}


de infecção esquistossomótica conhecido. Rev. Soc. Bras. Med. Trop., 5: 55-60, 1971.

5. KATZ, N., CHAVES, A. \& PELTEGRINO, J. - A simple device for quantitative stool thick-smear technique in schistosomiasis mansoni. Rev. Inst. Med. Trop. São Paulo, 14: 397-400, 1972 .

6. LEE, H G. CHEEVER, A. W., \& FAIRWEATNER, W. R. - Influence of parasite strain on chemotherapy of $\mathrm{mu}$ rine schistosomiasis mansoni. Bull. Wld Hlth Org., 45: 147- 155, 1971.
7. PELLEGRINO, J. \& KATZ, N. - EXperimental chemotherapy of schistosomiasis mansoni. Advances Parasitology, 6: 233-290, 1968.

8. ROGERS, S. H. \& BUEDING, E. Hycanthone resistence: development in Schistosoma mansoni. Science, 172: 1057-1058, 1971.

9. THOMPSON, P. E., MEISENHELDER, J. E., MOORE, A. K. \& WAITZ, J. A. - Laboratory studies on the joint effects of certain tris ( $p$-aminophenyl) carbonium salts and antimonials as antischistosomal drugs Bull Wld Hith Org 33: 517-535, 1965. 